\title{
Design of PCB Manufactured Low Cost Flexible Embedded Electronic Devices
}

\author{
Rifat Al Nahiyan \\ Department of Computer Science \& Information \\ Technology \\ Shanto Mariam University of Creative Technology \\ Uttara, Dhaka
}

\author{
Tasnim Niger \\ Department of Computer Science \& Engineering \\ Shanto Mariam University of Creative Technology \\ Uttara, Dhaka
}

\begin{abstract}
Portable electronics faster development has helped to acquire a slow but steady and high power output. With the PCB production technology, fabrication of high performance device at low cost and large-scale becomes feasible.

This paper introducing the idea of thinnest laptop/tablet \& digital watch, using printed circuit board (PCB) and flexible display. These devices can be run in windows and android platform. Overall thickness is minimum. These devices may be considered as future devices which can run by embedding PCB with other digital components. It's an attractive solution to improve the usability of digital devices.
\end{abstract}

\section{General Terms}

Embedded Electronic Device

\section{Keywords}

Printed circuit board (PCB), manufacturing, thin tab, digital watch, low cost, flexible, integrated client support.

\section{INTRODUCTION}

Now a days designers are contemplating adopting different method and interested to incorporate small footprint solutions within circuit designs to meet a wide variety of voltage/power regulation, logic controller, and clocking needs. They are doing this using small component body footprint and minimal area requirements. It is an ongoing process and with the development of the technology a lot of area is yet unexplored. Design process is an area to be looked at. Improvement of device performance irrespective of size reduction, reducing circuit interconnection, improved switching performance, manufacturing process, thermal performance, reliability or even flexibility can be done with embedment of printed circuit board (PCB).

The main forces driving the importance of product design and development are competition - internal and external to the company. In this connection we are planning to introduce a new device for all. The device has touch display. The thickness of these devices is only $2 \mathrm{~mm}$. This device has a magnetic keyboard for typing. The keyboard is also thin with thickness of $0.5 \mathrm{~mm}$. This paper work is based on the production of a PCB ready touch automated tab. These provide a means of achieving a touch activated touch. This paper work gives even an unskilled personnel opportunity to produce a touch activated switch. This is ideally useful for making touch operated tab and watches.

\section{PCB RELATED WORK}

Embedded devices are computing system compact by an object with different electronic devices and chips, used for special purposes. Electronic chips and circuits embedding in PCB reduces the device sizes and improved switching and thermal performance [1].

There are lot of assembling and disassembling methods and composition materials utilized with PCB [2-4]. Manufacturing firms have been developing new products since the industrial revolution [11-13]. The importance of designing and developing high quality new products has increased dramatically in recent years $[5,6]$.

Printed Circuit Boards are a vital part used with almost every electronic devices. To produce electronic devices with a range of sizes and physical shapes like cylinder PCB is essential. In addition, PCB is a new dimension can be go with 3D printing approach [15].

\section{INTERNAL STRUCTURE (LAPTOP/}

\section{TABLET)}

Surface-mount components having uniform thickness are used to prepare standard PCBs and thus allow to dense PCB staking [14].

Initially the device will be $2 \mathrm{~mm}$ thick, next target to make it $1 \mathrm{~mm}$ of thick. The keyboard is $0.5 \mathrm{~mm}$ of thick. The performance of this product depends on its motherboard. It is very light weight, easy to carry \& handy with low power consumption, low E-Waste counted material. The product price will be low and helpful for students.

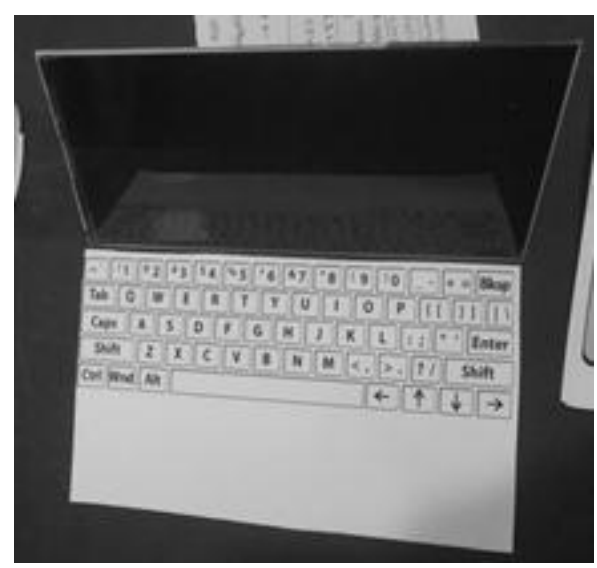

(a) 

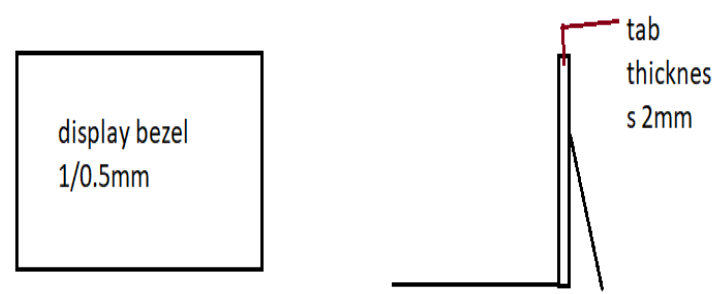

(b)

Fig 1: (a) Models of thin laptop, (b) Display size and thickness

\section{COMPONENTS OF THIN TAB 4.1 PCB (Printed circuit boards)/ Motherboard}

A sample of required system such as RAM 4gb, ROM 256gb, Graphics/VGA/AGP card 1gb, Display 10/12/14inch, Wi-Fi, bluetooth etc. The device mother board contains all these elements. All these chips should be in micro and the chips thickness without motherboard is about $1.3 \mathrm{~mm}$ and the layer thickness of PCB board about $0.2 \mathrm{~mm}$. The total thickness of this mechanism is about $1.3 \mathrm{~mm}[9,10]$. The connections of the PCB is with copper coated flexible plastic ribbon [8].

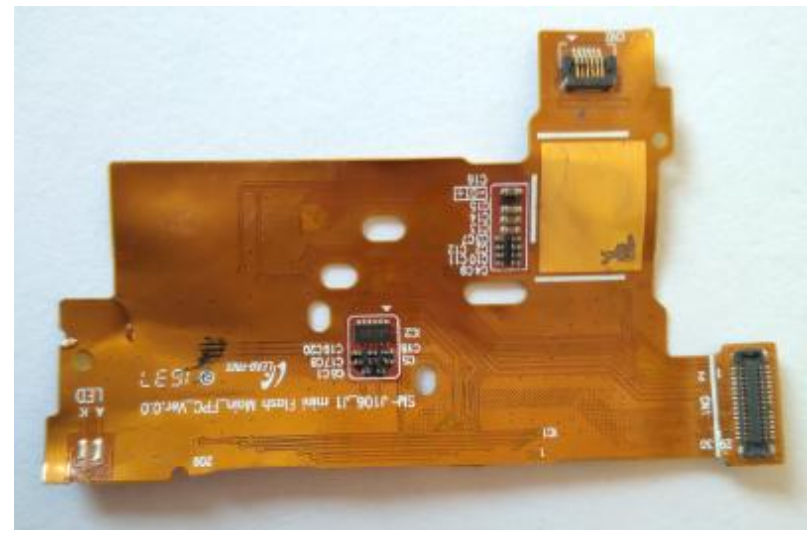

Fig 2: 1mm PCB Motherboard with Micro Chipset

\subsection{Maintaining the Integrity of the Specifications Casing:}

Casing is an important part of this device because of the durability. Total casing thickness is $2 \mathrm{~mm}$. It is divided into three sections. The two sections are used for 2 batteries. The one section is middle of the other two sections. The middle section used for $\mathrm{PCB} /$ motherboard. Other little sections are used for speakers, front \& back cam, sensors, magnetic ports etc. Such as the upper box of the design kept for front camera and back camera and for others sensor. Sensors means face detection or led flash light. Same type of space situated right or left side for using fingerprint sensor. Some space used for power on off keys and volume up or down keys. The gap space placed below of the casing is used for magnet ports so that we can use magnet keyboard from there. The whole casing made by Steel/ Aluminum. These steel or aluminum comes from $100 \%$ recycling. The three sections of the casing thickness is about $0.3 \mathrm{~mm}$ and rest of the other sides are $1.8 \mathrm{~mm}$ (Fig. 3). There are many boxes created besides the battery and motherboard. The battery backside and the wall of the casing are attached by glue. These will ensure hard durability on chassis of casing.

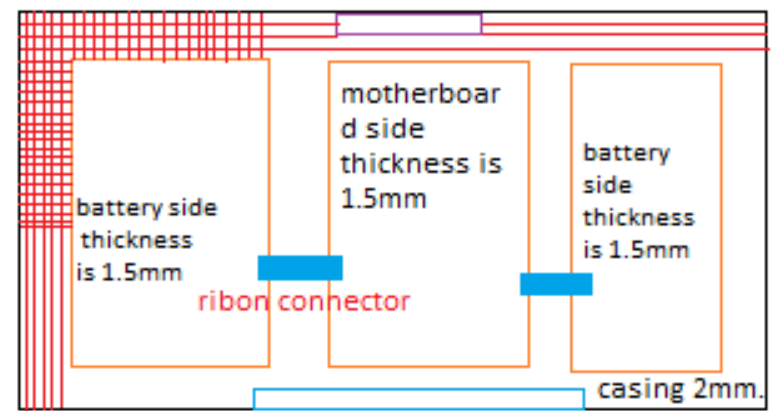

Fig 3: Casing design with equipment

\subsection{Display}

The main part of the product is its display. Display thickness is $0.1 \mathrm{~mm}$ [10]. It is flexible but not foldable and thin like a paper. The paper display is connected to PCB circuit board by copper ribbon of the middle of casing [8]. The total paper display placed all over the casing. The batteries and PCB circuit board are placed under the display. The display placing upon the total system there is a gap will be made itself. The gap filled by some type of liquid material that's get hard after cooling. So anyone can use the touch action on the display without making any difficulties [10].

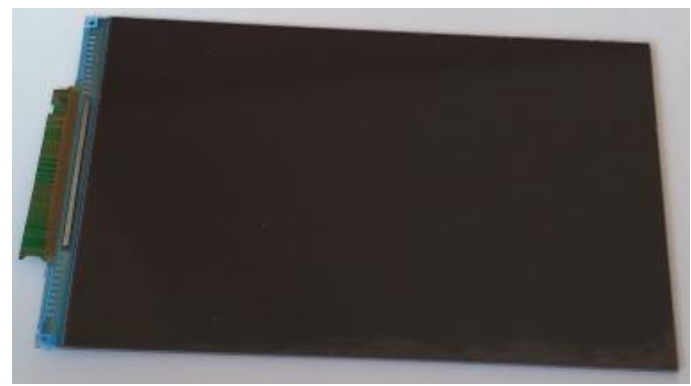

(a)

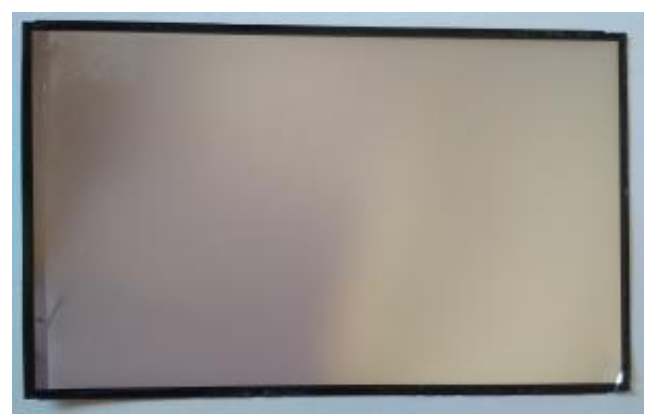

(b)

Fig 4: Flexible thin paper display (a) front size (b) backside

\subsection{Battery}

The battery of this device will be 20000 to $10000 \mathrm{MAH}$. It is connected to PCB circuit board by copper ribbon [8]. The battery thickness is about $1.5 \mathrm{~mm}$. They are attached to the casing by glue gun. The battery connects with motherboard to supply electric power to the motherboard, display, keyboards and other chips. It has two points such as positive and negative. 


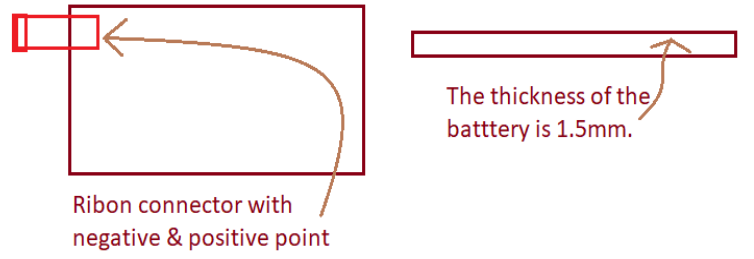

Fig 5: Battery placement

\subsection{OTA (Over the air)}

Now a days OTA getting very popular such as Bluetooth, WiFi file sharing, streaming movies, multi user games. This device is OTA featured. There is input and output device which has USB options to connect hard disk drive, USB solid state drive, pen drives, USB mouse or keyboard and also many other things as like as printer over the air.

\subsection{Ribbon}

Ribbon is thin copper coated wire which works as a wire to supply electricity and also data. They connects each parts inside of the slim tablet.

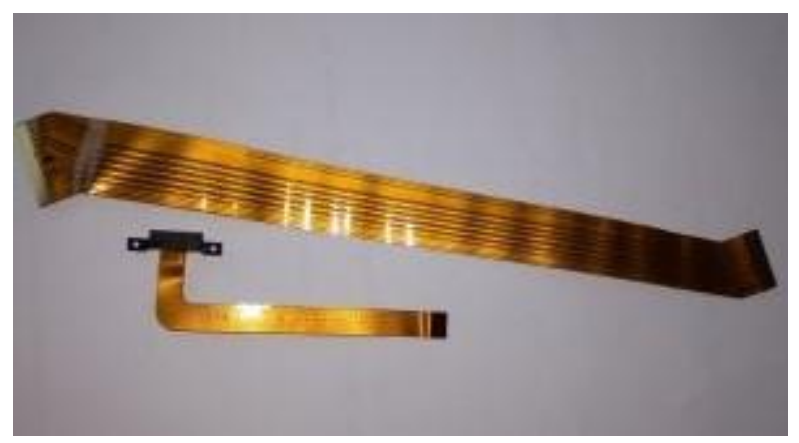

Fig 6: Ribbon for connection

It also makes a connection to display from motherboard and touch panel. Internal front, back and back camera also connected to motherboard by it [7].

\subsection{Keyboard}

Touch display laptop/tab needs a keyboard. This device has a magnetic keyboard for typing capability. The keyboard is important and it will be thin. The keyboard thickness is $0.5 \mathrm{~mm}$. It is made by metal and touch interface. The keyboard contains two touch options one is typing mode and the other one is touchpad mode. Metal furnished design makes it glossy. The main features of the keyboard is touch keyboard and two tap keyboard.

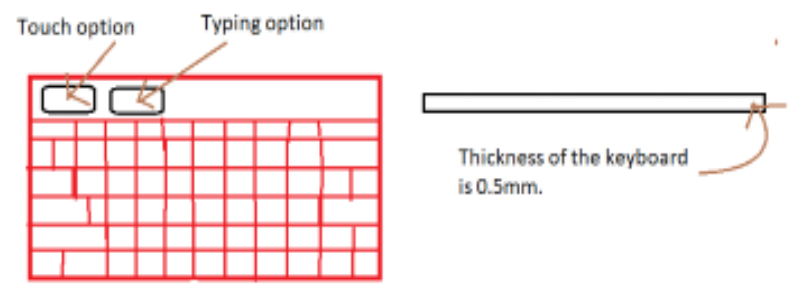

(a)

\begin{tabular}{|c|c|c|c|c|c|c|c|c|c|c|c|}
\hline$\therefore \quad 11$ & 92 & -3 & $\$ 4$ & $\% 5$ & ${ }^{\wedge} 6$ & $\& 7$ & .8 & 19 & 10 & & $+=$ Bksp \\
\hline Tab & w & E & $\mathbf{R}$ & $T$ & $r$ & u & I & 0 & F & $1 \mathrm{C}$ & [\}$][1]$ \\
\hline Caps & A & $\mathrm{s}$ & D & $\mathbf{F}$ & G & H & $J$ & K & L & $: ;$ & " ' Enter \\
\hline Shift & $\mathbf{z}$ & $\mathrm{x}$ & c & v & B & $\mathbf{N}$ & M & $<$, & $>$ & $?$ & Shift \\
\hline tri Wnd & Alt & & & & & & & & $\leftarrow$ & $\uparrow$ & $\downarrow$ \\
\hline
\end{tabular}

(b)

Fig 7 (a) (b): Keyboard structure and layout

All of these function on it is touch capable. The two tap options means that there are two touch option will be available top of the left corner of the keyboard. One option is used to turn on the touch pad mode and other option is used to turn on the key button mode for typing. All those action will be completed by one touch. The keyboard is also waterproof and dustproof. Backlit function also available in it while typing in dark room or dark places or at night.

So that user can use the touchpad system by whole interface easily and comfortably. The keyboard connected to laptop by magnetic sockets.

\section{DESIGN AND COMPONENTS OF DIGITAL WRIST WATCH}

Ultra-thin watch with a thickness of $1 \mathrm{~mm}$. Wide Ultra-thin display easy to see time-date -day. Unbreakable soft display has backlit panel. Very low power consumption, comfortable and very low contaminated/infectious. Auto time zone will be very useful.

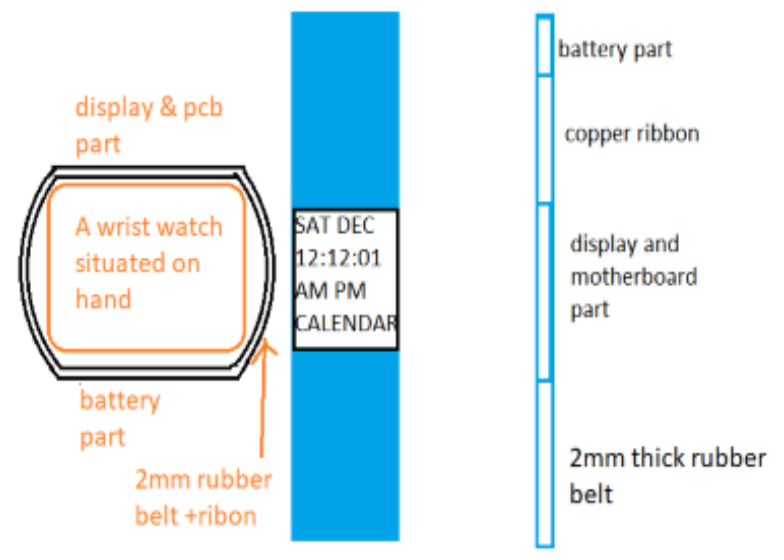

Fig 8: Internal \& external design of Digital wrist watch

\section{1 $\mathrm{PCB} /$ motherboard and display}

The display size may vary such as 1 inch to 2 inch and above. The paper display connect to PCB circuit board by copper ribbon of the middle of casing like as our proposed thin tab. Similarly display placing upon the total system there is a gap will be made itself and the gap filled by some type of liquid material that's got hard after its get cooled. We can use the touch action on the display without making any problem. Without touch option we can add soft press switch system to watch function.

We found such type of display that's thickness is $0.1 \mathrm{~mm}$. It is flexible not foldable yet $\&$ thin like a paper [9]. The paper display connect to PCB circuit board by copper ribbon. 


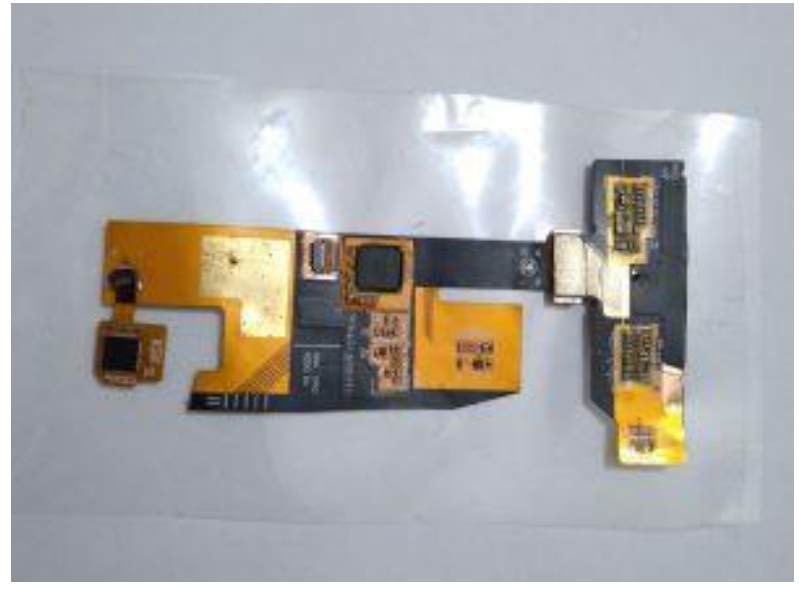

Fig 9: Flexible display with PCB motherboard

The total paper display placed upon the flexible $\mathrm{PCB} /$ motherboard [10]. The device motherboard contains chip elements that run the watch. According to all these chips should be in micro and the chips thickness without motherboard is about $1.3 \mathrm{~mm}$ and the layer thickness of PCB board is about $0.2 \mathrm{~mm}$. The total thickness of this mechanism is about $1.6 \mathrm{~mm}$. The whole part will be placed upon the wrist belt which thickness is about $0.4 \mathrm{~mm}$. But there may arise a question how? The answer is when the whole part placing upon the wrist belt there is a gap will be made itself. The gap filled by some type of liquid material that's got hard after getting cool. The connections of the PCB to battery with copper coated plastic ribbon (flexible). Our proposed system will show the Calendar like-day-hrs-min-sec-month.

\subsection{Battery}

The battery of this device may be coin sized/lithium battery connected to PCB circuit board by copper ribbon. The battery thickness is about $1.5 \mathrm{~mm}$. They are attached to the wrist belt. The battery is a lithium-ion and li-poly or rechargeable types. There is a micro USB option to charge the watch.

\subsection{Casing}

Casing is important part of this device because of the flexibility and light weight. The wrist belt is the case of this device to hold all these structure. Total thickness of the wrist belt is $2 \mathrm{~mm}$. It is divided into three sections. The one sections is used for $\mathrm{PCB} /$ motherboard and display [9] [10]. Another section is used for battery opposite side of display. The other section is middle of the another two sections, is used only copper ribbon to make a bridge connection between the both sides of parts [8].

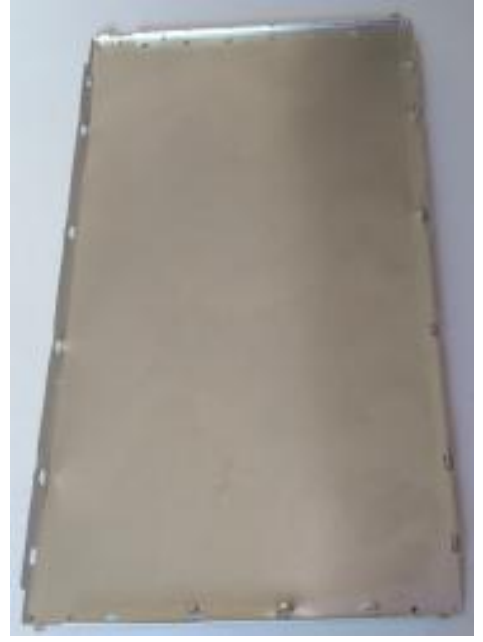

Fig 10: 2mm Aluminum Casing

\section{RESULT}

\subsection{Costing of Thin Tab}

Costing and price makes the benefits to the business. Target for these products are to make these popular and usable.

Next, Cost-Benefit Analysis were performed. The estimated prices are showing the costing difference between currently using laptops and our proposed thin tab. Price is in US Dollar. It may prefer each country. Total price for commonly used laptop is $\$ 300$ and total costing for our proposed thin tab is $\$ 230$. So, the difference is $\$(300-230)=\$ 70$. The thin laptop price is cheaper than today's laptops. It can change depending currency situation.

Table 1. Comparison of costing charge between traditional laptops and proposed tab

\begin{tabular}{|c|c|c|}
\hline Items & Today's laptops & $\begin{array}{l}\text { Proposed } \\
\text { Thin Tab }\end{array}$ \\
\hline Battery & $70 \$$ & $60 \$$ \\
\hline Motherboard & 60 & 40 \\
\hline Casing & 20 & 15 \\
\hline $\begin{array}{c}\text { Keyboard \& } \\
\text { mouse }\end{array}$ & $30 \$$ & 20 \\
\hline Display & 50 & 65 \\
\hline RAM & 20 & 10 \\
\hline SSD & $50 \quad \$$ & $20 \quad \$$ \\
\hline Servicing & Free & Free \\
\hline Total & $300 \$$ & 230 \\
\hline
\end{tabular}

\subsection{Costing of Digital Watch}

A chart costing of Thin digital watch is given below. The internal hardware of these devices may be little low cost comparing to other electrical wrist watches.

Cost-Benefit analysis were performed. Following estimated prices are the costing difference between currently using laptops and our proposed thin tab. Costing difference between Digital Watch and Proposed Thin Digital watch is $\$(57-46)=$ $\$ 7$. 
Table 2. Comparison of costing charge between traditional digital watch and proposed watch

\begin{tabular}{|c|c|cc|}
\hline Items & $\begin{array}{c}\text { Today's digital } \\
\text { watch }\end{array}$ & $\begin{array}{c}\text { Thin digital } \\
\text { watch }\end{array}$ \\
\hline Battery & $20 \quad \$$ & 15 & $\$$ \\
\hline Motherboard & $18 \quad \$$ & 15 & $\$$ \\
\hline Casing & Null & Null \\
\hline $\begin{array}{c}\text { Keyboard \& } \\
\text { mouse }\end{array}$ & Null & Null \\
\hline Display & $19 \quad \$$ & $16 \quad \$$ \\
\hline RAM & Null & Null \\
\hline SSD & Null & Null \\
\hline Servicing & Free & Free \\
\hline Total & $\mathbf{5 7} \mathbf{\$}$ & $\mathbf{4 6} \quad \mathbf{\$}$ \\
\hline
\end{tabular}

\section{CONCLUSION}

It's a rapidly developing technology of embedding PCB to make smart devices. At past time Electronics was so hard to understand and uncomfortable for user. Our goal to develop devices that everybody of all over ages can use easily and comfortably. Proposed thin tab can be placed everywhere like hospital, factories, constructions house etc. Students can use these devices easily and not too much weight to carry. The developed device can be used both domestic and industrial mechanism.

\section{ACKNOWLEDGMENTS}

The authors would like to thank the department of Computer Science and Engineering (CSE) and the department of Computer and Information Technology (CSIT) of Shanto Mariam University of Creative Technology for the fruitful support and Cooperation.

\section{REFERENCES}

[1] Cyril Buttay, Christian Martin, Florent Morel, Rémy Caillaud, Johan Le Leslé, et al.. Application of the PCBEmbedding Technology in Power Electronics - State of the Art and Proposed Development. 3D Power Electronics Integration and Manufacturing (3D-PEIM), Jun 2018, College Park, Maryland, United States. <hal01844981>

[2] B. Ferreira 2008. PCB Integration Technology Overview. ECPE Seminar of Power PCBs and Busbars. Delft 2008.

[3] Yang and C. C. Gordon 1993. Environmental threats of discarded picture tubes and printed circuit boards. J. Hazard. Mater., vol. 34, pp. 235-243, 1993.

[4] T. Fischer, J. Hahnlein, W. Haas, and V. Landes 1998. Organic substrates for environmentally friendly electronic devices. Circuit World, vol. 24, no. 4, 1998.
[5] Blessed Olalekan Oyebola, Eze Blessing E 2017. Touch Technology for Printed Circuit Board (PCB) Ready Automated Switch: A Smart Home Device. International Journal of Recent Engineering Research and Development (IJRERD) ISSN: 2455-8761 www.ijrerd.com || Volume 02 - Issue 11 || November 2017 || PP. 126-133.

[6] K S Aithal, Y Narahari and E Manjunath 2001. Modelling, analysis, and acceleration of a printed circuit board fabrication process. $\mathrm{S}^{-}$adhan ${ }^{-}$a, Vol. 26, Part 5, October 2001.

[7] Flexiblecircuit. Flexible printed circuits; [accessed 2019 dec12], https://www.flexiblecircuit.com/productcategory/flex-printed/

[8] Flexible PCB Market Growth Surging over Emerging Technologies. By Goldstein Research; 2018-02-03 [accessed $2019 \quad$ Dec 07]. https://www.goldsteinresearch.com/pressrelease/flexiblepcb-market-growth-surging-over-emerging-technologies.

[9] Flexible PCB [blog]. PCBWay. [accessed 2019 Nov 29]. https://www.pcbway.com/blog/Engineering_Technical/Fl exible_PCB.html

[10] PCBWay 2015. Let's build your own designs on flexible circuit boards. PCB Manufactuer In China, Shenzhen JDB Technology CO. LTD; Mar 05,2015 [accessed 2020 Jan $11]$ https://www.pcbway.com/project/share/Let_s_build_you r_own_designs_on_flexible_circuit_boards.html

[11] Ji, P.; Wan, Y. F. 2001. Planning for printed circuit board assembly: The state-of-the-art review. Int. J. Comput. Appl. Technol. 2001, 14, 136-144.

[12] LaDou, J 2006. Printed circuit board industry. Int. J. Hyg. Environ. Health 2006, 209, 211-219.

[13] Bonner, R. F.; Asselta, J. A.; Haining, F. W.1982. Advanced printed-circuit board design for highperformance computerapplications. IBM J. Res. Dev. 1982, 26, 297-305.

[14] Jianzhi Li, Puneet Shrivastava, Zong Gao, and HongChao Zhang , "Printed Circuit Board Recycling: A Stateof-the-Art Survey ," IEEE Transactions on Electronics Packaging Manufacturing, VOL. 27, NO. 1, JANUARY 2004

[15] Kenneth H. Church, Harvey Tsang, Ricardo Rodriguez, Paul Defembaugh, Raymond Rumpf 2013. Printed Circuit Structures, the Evolution of Printed Circuit Boards. Published in the IPC APEX Info Conference Proceedings. 